\title{
An Ecotoxicological Approach to Assess the Environmental Quality of Freshwater Basins: A Possible Implementation of the EU Water Framework Directive?
}

\author{
Bettinetti Roberta *, Ponti Benedetta and Quadroni Silvia \\ DiSTA, University of Insubria, Via Valleggio 11, 22100 Como, Italy; \\ E-Mails: benedetta.ponti@uninsubria.it (P.B.); silvia.quadroni@uninsubria.it (Q.S.) \\ * Author to whom correspondence should be addressed; E-Mail: roberta.bettinetti@uninsubria.it; \\ Tel.: +39-031-238-6484.
}

Received: 16 May 2014; in revised form: 4 August 2014 / Accepted: 4 August 2014 /

Published: 20 August 2014

\begin{abstract}
Within the context of the Water Framework Directive, the need to identify new monitoring tools in support of the traditional chemical monitoring process is emerging. Chemical characterization by itself does not provide specific biological information about potential hazards to organisms, in particular when facing cocktails of contaminants. Therefore, ecotoxicity tests can represent a useful tool supporting the chemical information. In the present work, the value of ecotoxicity tests as an effect-based tool for monitoring freshwater and sediment quality of the south-western basin of Lake Como (Northern Italy) was evaluated, assessing the potential risk of pollutants. Results obtained from $D$. magna toxicity tests showed a temporal variation of toxic response in relation to the variability of organic micropollutant load characteristics of urban rivers. Sediment ecotoxicity test data showed the spatial variability of the sediments' contamination within the lake, confirmed by chemical analysis of two classes of pollutants (dichlorodiphenyltrichloroethane (DDT) and polychlorobiphenyls (PCB)). The observed effects on organisms in laboratory tests caused by a mixture of almost unknown chemicals underline the importance of integrating effect-based tools into monitoring efforts.
\end{abstract}

Keywords: sediment ecotoxicity tests; freshwater ecotoxicity tests; biomonitoring; effect-based tools; organic micropollutants 


\section{Introduction}

The Water Framework Directive (WFD 2000/60/EC) is the European Union directive to protect the water environment, which commits EU Member States to achieve "a good qualitative and quantitative status" of all water bodies by 2015, prescribing steps to reach the common goal rather than adopting a more traditional limit value approach [1]. The achievement of the ecological status requested by the law implies a complete outline of the present situation as a starting point for future improvement measures. Therefore, screening ecosystem quality through an integrated approach, which takes into account the biological/ecological effects of contaminants, is requested. The detection of effects by multiple stressors, chemical substances in particular, at an early stage, is of importance for the conservation of the environment. Ecotoxicological tests can be a valid tool to indicate the hazards of toxicants, which can be present as complex mixtures in the environment, in unknown or simply not analyzed components. The WFD requires Member States to analyze priority substances (33, with another 12 recently added; Annex II 2013/39/EC) in monitoring programs, but as far as we know, only $75 \%$ of these contaminants can be reliably monitored in water with acceptable uncertainty when applying existing standardized analytical methods [2,3]. Therefore, at present, a lack of information on the concentrations of the priority pollutants requested by the Directive still exists, with some sporadic exceptions [4-6].

Although laboratory bioassays are not explicitly prescribed by the WFD to assess the quality of the aquatic environment, the application of effect-based monitoring in the basin management is warmly supported by the European Commission [7-9]. In the case of freshwater environments, the main standard organism for the water column quality laboratory evaluation is the crustacean, Daphnia magna. Among the possible contaminants, organic micropollutants are present in water at concentrations that rarely cause acute toxic effects, but might pose a threat when long-term exposure periods are considered [10]. A practical methodology to define the quality of surface water validated on a number of surface waters from the Po River basin (Italy) by Galassi et al. [11-13] seems therefore particularly appropriate. Since most of the contaminants can be extracted from water samples by a single solid-phase extraction (SPE) procedure using LiChrolut cartridges [14], the extracted compounds can be tested using Daphnia magna at concentrations higher than those observed in the original water samples through short-term exposures, which are more easily conducted than chronic exposures, and for the overall quality of a water body, with regard to micropollutant contamination, the effect concentrations can be evaluated quickly and simply and compared to hazard ranking values based on concentration factors (CF) [13].

The contamination of aquatic ecosystems also concerns sediments; hydrophobic contaminants in particular can be bioavailable and of several orders of magnitude higher than in the overlying water, causing a risk to benthic organisms. While the essential role of the sediments of water ecosystems is widely recognized, environmental quality standards are not yet established at the European level, and concentrations in sediments are mainly measured to assess long-term impacts of anthropogenic activity and trends [15]. At present, weight-of-evidence approaches, such as the sediment quality triad [16,17], are widely accepted to assess the ecological risk of sediment-bound contaminants, but the setting of environmental quality standards as done for surface water is still in its early stages. Over the years, research has demonstrated that sediments exceeding sediment quality guidelines do not always result 
in toxic effects on benthic organisms, and sometimes, even the opposite has been observed, probably due to the different bioavailability of contaminants [18]. In addition to chemical analysis and in situ benthic community assessment, ecotoxicity testing with single species could therefore be particularly useful.

In the present work, we report the results obtained during a first-step master plan to characterize the ecological quality of the southern-west branch of the Como basin (Lake Como, Northern Italy), one of the deepest lakes in Europe. The aim is to propose the application of an ecotoxicological approach as a "switch on/off strategy to evaluate the state of contamination of a freshwater basin"; this method should allow the selection of samples where the effects are ascribable to a cocktail of contaminants for more detailed further characterization.

\section{Materials and Methods}

\subsection{Study Area and Sampling Sites}

Lake Como is the deepest (maximum depth $=425 \mathrm{~m}$ ) southern-alpine Italian lake. It has three branches of approximately equal length; the south-westward basin is closed in its southern part by the city of Como (around 85,000 inhabitants), in an area particularly impacted by industrial, agricultural and urban activities. This basin is supplied by the water of two main tributaries: River Breggia and River Cosia. River Cosia grows out of Monte Bollettone (IT), and in its final part, it passes through the city, canalized and mainly underground. In its final section, it receives waters from the sewage treatment plant, Comodepur SpA. River Breggia grows out of Monte Generoso (IT), and after $2.5 \mathrm{~km}$, the river enters Switzerland, where it receives waters from a sewage treatment plant. In the final section, River Breggia comes back into Italy and flows into the lake. Both rivers are typically urban with a high anthropogenic impact.

On the basis of this information, a total of seven water samples, $16 \mathrm{~L}$ each, were collected, using a bucket lowered from the bridges at the rivers and using a Niskin bottle in the lake at a depth of $45 \mathrm{~m}$ corresponding to the water supply for potable uses of the city (Figure 1). Samples were transferred in dark glass bottles $(2.5 \mathrm{~L})$ and stored at $4{ }^{\circ} \mathrm{C}$ until laboratory preconcentration/tests. River Cosia was sampled at its uncovered stretch before where the sewage treatment plant water flows into the river in 2007 (Cosia 07) and 2008 (Cosia 08) and at its estuary in 2008 (CosiaF 08), 2012 (CosiaF 12) and 2013 (CosiaF 13). River Breggia was sampled at its estuary in 2012 (Breggia 12) and Lake Como was sampled in 2012 (Como 12).

Sediment samples were collected in summer, 2013, with a steel grab in the southern part of the south-westward basin of Lake Como: three samples (Sites 1, 2 and 3, Figure 1) in the Como city basin and one sample (Site 4) in the northern part of the same basin outside the influence of the city at a depth of $10 \mathrm{~m}$ (Figure 1). Site 1 was sampled in an undisturbed area next to the mouth of River Cosia at a depth of $15 \mathrm{~m}$; sediments of Site 2 were collected corresponding to the water intake for potable uses at a depth of $40 \mathrm{~m}$; Site 3 was sampled in the harbor of the city at a 10-m depth. Sediments were stored at $4 \pm 1{ }^{\circ} \mathrm{C}$ in the dark and sieved $(250 \mu \mathrm{m})$ prior to the test, which started within three weeks of collection. The organic matter content of the sediments was determined by weight loss-on-ignition (LOI) at $550{ }^{\circ} \mathrm{C}$ in a laboratory [19]. 
Figure 1. Map of Lake Como with sample sites. The bullets show different water sample points with the sampling year. Stars show sediment sample sites. The arrow indicates the inflow of the wastewater treatment plan into the Cosia River.

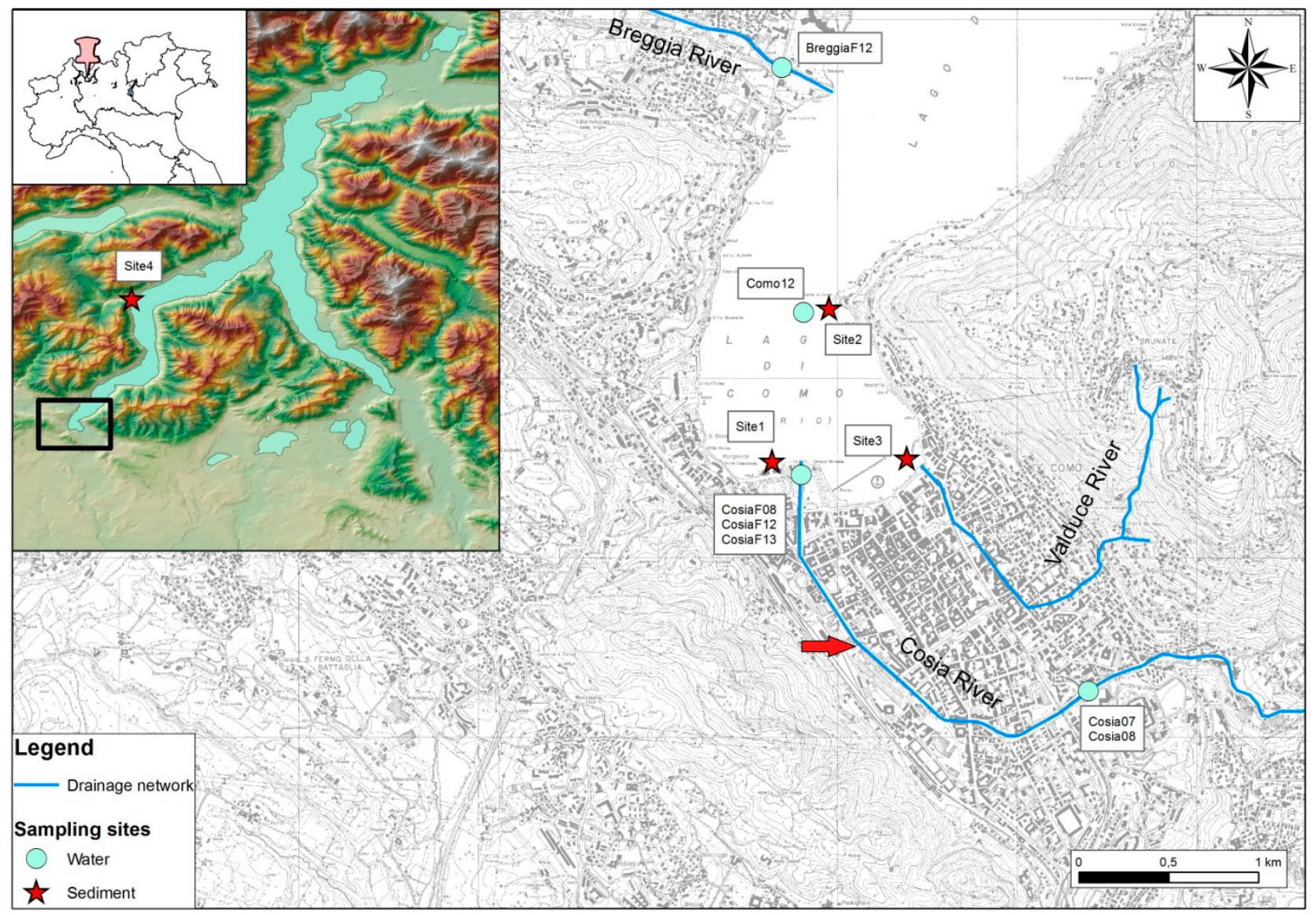

\subsection{Lake Como Basin's Contamination History}

Lake Como and in particular its south-western branch, where the major city is located and no river outlet is present, has been of interest for several decades because of water quality problems. The lake experienced intense eutrophication during the 1960s, which has only been partially solved in more recent years. At present, its trophic status is meso-eutrophic on the whole (Total Phosphorus concentrations: $30-40 \mu \mathrm{g} / \mathrm{L}$ [20], but particularly high phosphorus concentrations are still present in the Como branch, which is a "closed" basin. The lake and, in particular, its west-southern branch has a long history of chemical contamination due to the several industrial and agricultural activities within the basin. Some previous studies mainly focused on the evaluation of the water lake quality as an alternative supply for drinking uses, having shown mutagenic activity in the 1980-1990s [21-23]. Contaminants, such as hexachlorobenzene, benzophenone, DDT, PCB and $\alpha$ - and $\gamma-\mathrm{HCH}$, were quantified in 1997 [24] in two sites of the Como basin, and within these studies, the River Cosia was identified as an important source of mutagenic contamination, being therefore the main contamination source of mutagens in the lake [23]. Information on the contamination of sediments goes back to the 1990s. The analyses of the main organic micropollutants in sediments, collected in 1991 near to the site where water is collected for drinking uses (Figure 1, Site 2), revealed a contamination by polychlorobiphenyls higher than other large lakes in Northern Italy in that period (Lake Maggiore and 
Lake Garda) [25]; the same has been confirmed by a further study on PCB [26]. With respect to dichlorodiphenyltrichloroethane, concentrations in the Como basin were particularly high during the period of its use in the 1970s; they were around $15 \mathrm{ng} / \mathrm{g} \mathrm{d.w}$. [27] in 1991 and $54 \mathrm{ng} / \mathrm{g} \mathrm{d.w}$. in 2009 [28].

Heavy metals, analytically determined in 1992 in sediments, confirmed a considerable contamination of the Como basin, particularly of copper and zinc [26]. Recent research on mercury pollution, by analyzing sediments, showed high mercury enrichment $(1 \mathrm{mg} / \mathrm{kg} \mathrm{d} . \mathrm{w}$. in recent years, above a background value of $0.1 \mathrm{mg} / \mathrm{kg} \mathrm{d.w.)} \mathrm{[29].}$

\subsection{Solid Phase Extraction and Concentration of Water Samples}

Water samples taken at each site were filtered on $0.45-\mu \mathrm{m}$ cellulose acetate filters and passed through LiChrolut EN cartridges (500 mg, Merck, Darmstadt, Germany) for organic micropollutant extraction.

The cartridges were previously washed with $10 \mathrm{~mL}$ of methanol, $10 \mathrm{~mL}$ of acetone and $100 \mathrm{~mL}$ of Milli-Q water, and the water sample concentration was performed using a vacuum pump at a flow rate of $8 \mathrm{~mL} / \mathrm{min}$. Samples were passed through the cartridges ( $4 \mathrm{~L}$ for each $500 \mathrm{mg}$ cartridges; 4 cartridges for each sample site) and dried, and then, they were eluted with $10 \mathrm{~mL}$ of acetone. The solvent was evaporated to a final volume of $20 \mu \mathrm{L}$, and the concentrated extract was added to $100 \mathrm{~mL}$ of the Daphnia magna water medium; the "stock solution" was diluted to obtain different concentration factors (CF) (between 2.5× and 80×) [13]. CF represents the ratio between the concentration of the extracted organic micropollutants occurring in the reconstructed samples used in the ecotoxicological tests and their concentration in the original water samples, assuming a quantitative recovery. A hazard characterization for surface waters based on CF causing toxicity to Daphnia magna has been proposed and applied by Galassi et al. [13].

\subsection{Acute Tests with Daphnia magna}

Daphnia magna acute tests were performed according to the OECD Guideline 202 [30]. The test medium was the same commercial mineral water $\left(\mathrm{pH} 7.8\right.$, hardness $\left.240 \mathrm{mg} \mathrm{CaCO}_{3} / \mathrm{L}\right)$ used as the culture medium. Neonate daphnids born by parthenogenesis (age $\leq 24 \mathrm{~h}$ ) were exposed to different CFs in four replicates $(25 \mathrm{~mL})$. For each replicate, five individuals were used and daphnid immobilization was observed after $48 \mathrm{~h}$. Control tests, one with the water medium only and one with the medium added with acetone $(0.25 \mathrm{~mL} / \mathrm{L})$, were also performed.

A blank test was carried out, passing $5 \mathrm{~mL}$ of acetone through a cartridge and concentrating the extract to $20 \mu \mathrm{L}$. The concentrated elute was added to $100 \mathrm{~mL}$ of water medium, as in the case of water extracts. No toxic effects were observed.

\subsection{Sediment Analyses}

Sediments were characterized in terms of two classes of pollutants, polychlorinated biphenyls (PCB 28, PCB 52, PCB 101, PCB 118, PCB 138, PCB 153, PCB 180) and dichlorodiphenyltrichloroethane and its metabolites (p,p'-DDT, o,p'-DDT, p,p'-dichlorodiphenyldichloroethylene (p,p'-DDE), o,p'- 
DDE, p,p'-dichlorodiphenyldichloroethane (p,p'-DDD), o,p'-DDD). For persistent organic pollutants (POP) determination, the extraction of freeze-dried homogenized sediments $(1 \mathrm{~g})$ was performed in glass microfiber thimbles (19-mm internal diameter $\times$ 90-mm external length, Whatman, England) for $2 \mathrm{~h}$ with $60 \mathrm{~mL}$ of $\mathrm{n}$-hexane (Carlo Erba, Italy, pesticide analysis grade) using a modified Soxhlet apparatus (Velp Scientifica-ECO 6 thermoreactor). Chlorinated compounds were recovered by several $n$-hexane washings, and extracts were concentrated down to $c a .2 \mathrm{~mL}$ and passed through a Florisil column (4-cm length, $0.7-\mathrm{cm}$ diameter) with $\mathrm{Cu}$ powder $(0.1 \mathrm{~g})$ on the top. $\mathrm{Cu}$ powder was previously activated by $\mathrm{HCl}(18 \%$, Carlo Erba, Italy) and washed with water, acetone and $n$-hexane. The Florisil column was eluted with $25 \mathrm{~mL}$ of n-hexane-dichloromethane (Carlo Erba, Italy, pesticide analysis grade) using a 85:15 (v/v) mixture, and the eluate was concentrated to exactly $0.5 \mathrm{~mL}$. The purified extracts were analyzed by gas chromatography (GC Carlo Erba, Top 8000) coupled with a 63Ni electron capture detector (Carlo Erba ECD 80) using an on-column injection system (volume injected: $1 \mu \mathrm{L}$ ). The column was a wall coated open tubular column fused silica CP-Sil-8 CB (50 $\mathrm{m} \times$ $0.25 \mathrm{~mm}$ I.D., film thickness $0.25 \mu \mathrm{m}$, Varian, USA). The temperature program used was from $60{ }^{\circ} \mathrm{C}$ to $180{ }^{\circ} \mathrm{C}$ at $20{ }^{\circ} \mathrm{C} / \mathrm{min}$, followed by a run from $180{ }^{\circ} \mathrm{C}$ to $200{ }^{\circ} \mathrm{C}$ at $1.5{ }^{\circ} \mathrm{C} / \mathrm{min}$. A further run was implemented from $200{ }^{\circ} \mathrm{C}$ to $270{ }^{\circ} \mathrm{C}$ at $3{ }^{\circ} \mathrm{C} / \mathrm{min}$ followed by a final isothermal maintenance at $270{ }^{\circ} \mathrm{C}$ for $20 \mathrm{~min}$, with helium as the carrier gas $(1 \mathrm{~mL} / \mathrm{min})$ and nitrogen as the auxiliary gas $(30 \mathrm{~mL} / \mathrm{min})$. Sample quantification was performed using external reference standards of pp'DDT, pp'DDE and pp'DDD (Pestanal, Sigma-Aldrich, Germany) in iso-octane (Carlo Erba, Italy, pesticide analysis grade). AROCLOR 1260 (Alltech, IL, USA) with the addition of PCB 28, 52 and 118 was used for PCB quantification. The sum of the analyzed PCBs corresponds by weight to about $97 \%$ of the reference standard. The detection limit for each organochlorine compound was $0.1 \mathrm{ng} / \mathrm{g} \mathrm{d} . \mathrm{w}$. The recovery efficiency was tested on a reference sediment previously used in an inter-calibration exercise [31] and was within $80 \%-100 \%$ for the three DDT homologues and HCB and around $90 \%$ for each PCB congener. Every batch of 5 core slices was analyzed in association with the reference sediment. POP data are presented as concentrations (expressed as ng) on the dry weight of sediments.

\subsection{Chironomus riparius Culture and Bioassay}

The test organism, Chironomus riparius, was bred at $21 \pm 1{ }^{\circ} \mathrm{C}$ under a $16: 8$-h light:dark photoperiod in 40-L aquaria with control sediment $(3 \mathrm{~cm}$ deep; the formulation of the sediment is recommended by [32] as the substrate. An $8 \mathrm{~cm}$-deep column of dechlorinated tap water (hardness: $320 \mathrm{mg} / \mathrm{L} \mathrm{CaCO}_{3}$ ) was maintained over the sediment. The cultures were fed weekly with $1 \mathrm{~g}$ $\operatorname{Tetramin}^{\circledR}$ fish food per tank, and the water almost completely renewed at that time. The first-instar larvae for use in the experiment were obtained by transferring egg ropes from the culture to glass vessels containing spring water. The time required to hatch the first instar larvae was about 3 days at $21 \pm 1$ ${ }^{\circ} \mathrm{C}$. The animals were then transferred randomly to each test beaker with a glass pipette, putting them below the water surface to avoid trapping them in the surface film.

Tests were performed according to [32]. One day before the addition of first-instar larvae, 250-mL glass beakers were filled with $70 \mathrm{~g}$ of wet sediment (water content about $50 \%$ ) and $200 \mathrm{~mL}$ of dechlorinated water; $3.5 \mathrm{~mL}$ of a $4 \mathrm{~g} / \mathrm{L}$ water suspension of fish food, corresponding to $14 \mathrm{mg}$ d.w. Tetramin, were put in each beaker. 
The contents of the beakers, covered with a plastic Petri dish with a hole for aeration, were allowed to settle in the dark $21 \pm 1{ }^{\circ} \mathrm{C}$ for $24 \mathrm{~h}$. Six replicated beakers were prepared for each site sediment, including the control. At the start of the test, the overlying water of each beaker was gently aerated for $2 \mathrm{~h}$, and then 10 first-instar larvae, chosen at random, were transferred to each beaker. Tests were performed under a 16:8-h light:dark photoperiod for 28 days. Every 3 days, the animals were fed with $3.5 \mathrm{~mL}$ Tetramin suspension, and the water lost to evaporation was re-added. Temperature, $\mathrm{pH}$ and dissolved oxygen were measured in all of the beakers before and at the end of the tests, when ammonium was also recorded (ammoniac kit test). After the first 10 days, three replicates for each site were analyzed: total survival was noted and the individual larval wet weight of each larva recorded. Animals were placed in clean tap water for $6 \mathrm{~h}$ to purge the gut [33], then, they were dried on a filter paper immediately after removal. Their wet weights were recorded using a sensitive, nondestructive technique with an analytical balance [34,35]. Final larval weights were considered because they represent an integration of physiological responses that are known to be affected by the environment and by pollutant stress [36]. The remaining replicas were performed under the conditions described above till the end of the test. The total number of fully-emerged male and female midges was recorded daily. The maximum test duration was 28 days, and if midges emerged earlier, the test was ended 5 days after the last adult emerged in the control. Taking into account these indications, the present test lasted 25 days. Data in graphics are reported as the average values of the different replicates $( \pm$ standard deviation).

\subsection{Data Analysis}

The effect concentration (EC) for the 48-h Daphnia magna test (48 $\mathrm{h} \mathrm{EC}_{50}$ ) was estimated by probit analysis using the EPA Probit analysis program. Concentration factors were used as input data-concentrations.

One-way ANOVA was performed $(\alpha$ level $=0.05)$ followed by the post hoc Dunnett's test to evaluate the significance of the differences between each endpoint and control using STATISTICA 8 package (StatSoft). Data were log-transformed or square root-transformed when the assumptions of ANOVA (homogeneity of variances and independence of variance from the mean) were not attained [37]. Emergence data expressed as percentages were arcsin transformed before ANOVA.

The mean development rate, which represents the portion of larval development that takes place per day, was calculated according to [32]:

$$
x=\sum_{i=1}^{m} \frac{f_{i} \mathrm{x}_{i}}{n_{e}}
$$

where:

$x$ : mean development rate

$i$ : index of inspection interval

$m$ : maximum number of inspection intervals

$f_{i}$ : number of midges emerged in the inspection interval $i$

$n_{e}$ : total number of midges emerged at the end of experiment

$x_{i}$ : development rate of the midges emerged in interval $i$. 


\section{Results and Discussion}

\subsection{Water}

The information on the current quality status of the Lake Como basin, recognizable as a critical area from an ecotoxicological point of view, is undoubtedly lacking and dated.

Exposure to none of the water samples affected the mobility of D. magna, excluding direct acute effects. However, severe effects can be expected for chronic exposure [38], for example as a result of interactions between micropollutants [39-41]; pre-concentration by SPE allows the simulation of increasing environmental exposure to a mixture of organic micropollutants. A short-term exposure test on increasing concentrations can provide a useful and rapid evaluation of environmental quality as a screening tool, when compared with the hazard levels reported for other freshwater basins [13].

The validity criteria of the Daphnia magna acute test were fulfilled, since the dissolved oxygen concentration at the end of the test was above $2 \mathrm{mg} \mathrm{L}^{-1}$ and no daphnids were immobilized in the controls. Daphnia magna acute test results (Figure 2) point out similar responses in both river samples. A lower value was estimated for Lake Como water, but the variability of the $\mathrm{EC}_{50}$ value covers statistical differences. In any case, the reported value for Lake Como water quality is noteworthy, considering that the lake water is used for drinking purposes.

Figure 2. Daphnia magna acute $\mathrm{EC}_{50}$ values (95\% confidence limits) at each sample site. ECs refer to the concentration factors.

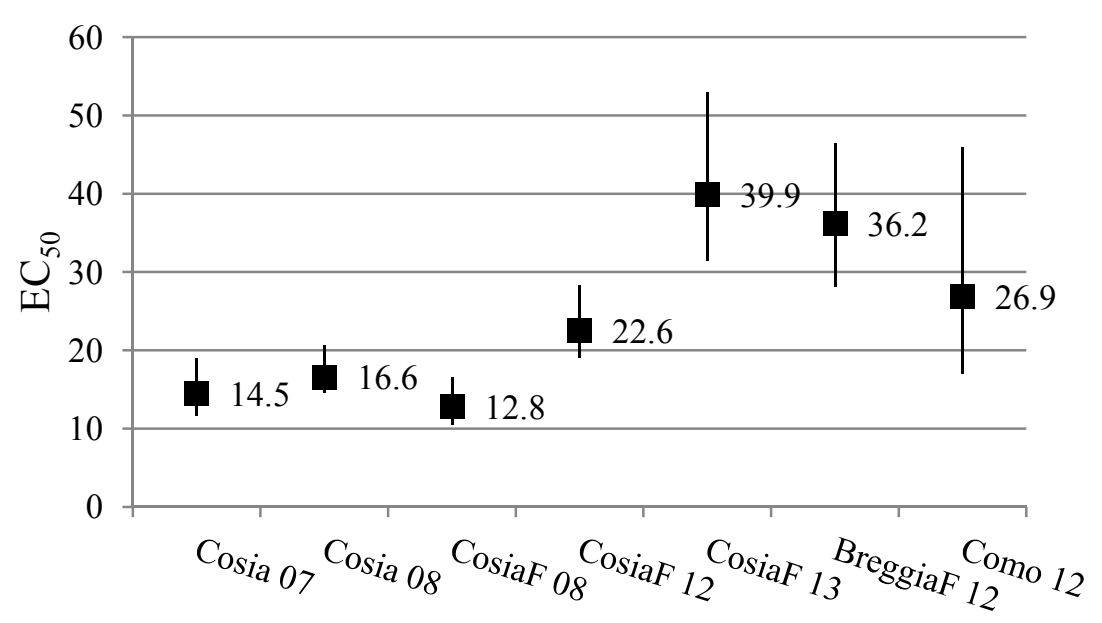

River Cosia increased its quality through time: the most recent value of $39.9 \times$, even considering its variability range, is significantly higher than the effect concentration measured starting from 2007 (Figure 2). Therefore, a temporal (between CosiaF sampling sites) and a spatial (among all of the sampling sites) variability of toxic responses was observed (Figure 2). As already found in other studies (e.g., [42]), time and space play important roles in the pattern of contamination: sampling time, in particular, may be responsible for the variability of the responses due to rainfalls or dry periods and different industrial activity. Unfortunately, the flow rate of River Cosia is not routinely monitored for logistic problems, since it flows covered and access is difficult; therefore, a 15-day average rainfall before sampling was considered for its estimation. In general, there is no obvious relationship between 
ecotoxicity and hydrologic data, even if in 2012 and 2013, a relationship between the average rainfall and the ecotoxicity of River Cosia water could be found, indicating a "dilution effect" of rain water. Other numerous factors should be considered, and no evident relationship was observed in 2007 and 2008, since the $\mathrm{EC}_{50 \text { s }}$ were similar, independent of rainfall. Considering that the major impact of this river is represented by industrial activities and wastewater treatment plant effluent (Figure 1), as for other urban rivers [43], the lower production of industry due to the global financial crisis of recent years (the average annual industrial waste flow rate decreased by $23 \%$ in 2012; Comodepur SpA) may be responsible for the water quality increase. In the case of the River Breggia, the water quality seems comparable to that of River Cosia in 2013, despite the low flow rate at the sampling date $\left(0.99 \mathrm{~m}^{3} / \mathrm{s}\right)$. Using the hazard characterization for surface waters based on concentration factors (CF) causing toxicity to Daphnia magna [13], all samples collected in 2012 should be considered with a low hazard for aquatic life, while a medium hazard for River Cosia was observed in 2007 and 2008. As the proposed procedure allows the discrimination between water samples according to the toxicity of the extractable toxic substances, it seems reasonable to use threshold CFs on D. magna [13] for screening purposes to assess water quality as an effect-based tool.

\subsection{Sediments}

The WFD directs Member States to develop sediment quality standards with the clear scope for the consideration of sediment quality as an integral part of water basin management. The recent Environmental Quality Standards (EQS) Directive 2013/39/EU (which amends the Directives 2000/60/EC and 2008/105/EC) marks an important step in the possible use of sediments and biota as matrices for chemical-status assessment; at present, some EQS are reported for biota, but not yet for sediments [2]. As for water, the ecotoxicological evaluation of the quality of sediments seems therefore particularly appropriate.

The first instar larvae of Chironomus riparius used in this study showed acceptable and constant sensitivity to $\mathrm{K}_{2} \mathrm{Cr}_{2} \mathrm{O}_{7}$ toxicity: the $96 \mathrm{~h} \mathrm{LC}_{50}$ to larvae was $14.1 \mathrm{mg} / \mathrm{L}$ (12.7-15.5), being lower than the sensitivity range indicated by [44] for second instar larvae. The LOI of the sediments, reported in Table 1, are quite similar to the reconstructed control sediment (12.3\%). From the beginning until the end of the test, $\mathrm{pH}$ differences among beakers were minimal (around $0.2 \mathrm{pH}$ units), and the oxygen saturation and ammonia values were constant and within the ranges reported by [32].

Table 1. Concentrations (ng/g d.w.) of dichlorodiphenyldichloroethylene (DDE), p,p'-dichlorodiphenyldichloroethane (DDD), dichlorodiphenyltrichloroethane (DDT) polychlorobiphenyls (PCB) in sediment samples. Organic matter content is expressed as \% of loss-on-ignition (LOI).

\begin{tabular}{lcccc}
\hline Column Heading & Site 1 & Site 2 & Site 3 & Site 4 \\
\hline LOI \% & 13.7 & 12.1 & 14 & 14.1 \\
pp'DDE & 1.2 & 3.7 & 16.5 & 2.5 \\
op'DDD & 1.8 & 2.4 & 14.1 & 4.8 \\
pp'DDD & 0.6 & 1.0 & 7.4 & 1.2 \\
op'DDT & 0.1 & 0.3 & 1.4 & 0.4 \\
pp'DDT & 0.2 & 0.6 & 1.8 & 0.5 \\
PCB total & 20.9 & 30.8 & 194.5 & 56.3 \\
\hline
\end{tabular}


The 10-day exposure test showed no significant differences in chironomid survival between sites and control (CNT), with the exception of Site 3 (Dunnett's post hoc test, $p<0.05$ ), which was significantly lower than the control (Figure 3). This difference was even more evident $(p<0.005)$ in terms of growth assessed as the wet weight of each larva; an impact was also observed on organisms grown in the sediment of Site 1 , which were significantly smaller $(p<0.05)$ than those of CNT. The analysis of weights allowed for the more effective pointing out of spatial differences in the contamination of the Como basin.

Figure 3. 10-days chironomids exposure test. (a) The percentage of chironomid larvae surviving in the control $(\mathrm{CNT})$ and at each site $( \pm \mathrm{SD})$ after 10 days of exposure; (b) the average wet weight (W.W. \pm SD) of chironomid larvae after 10 days of exposure. Significant differences (one-way ANOVA, Dunnett's post hoc test; $p<0.05 *$ ) with the control are reported.

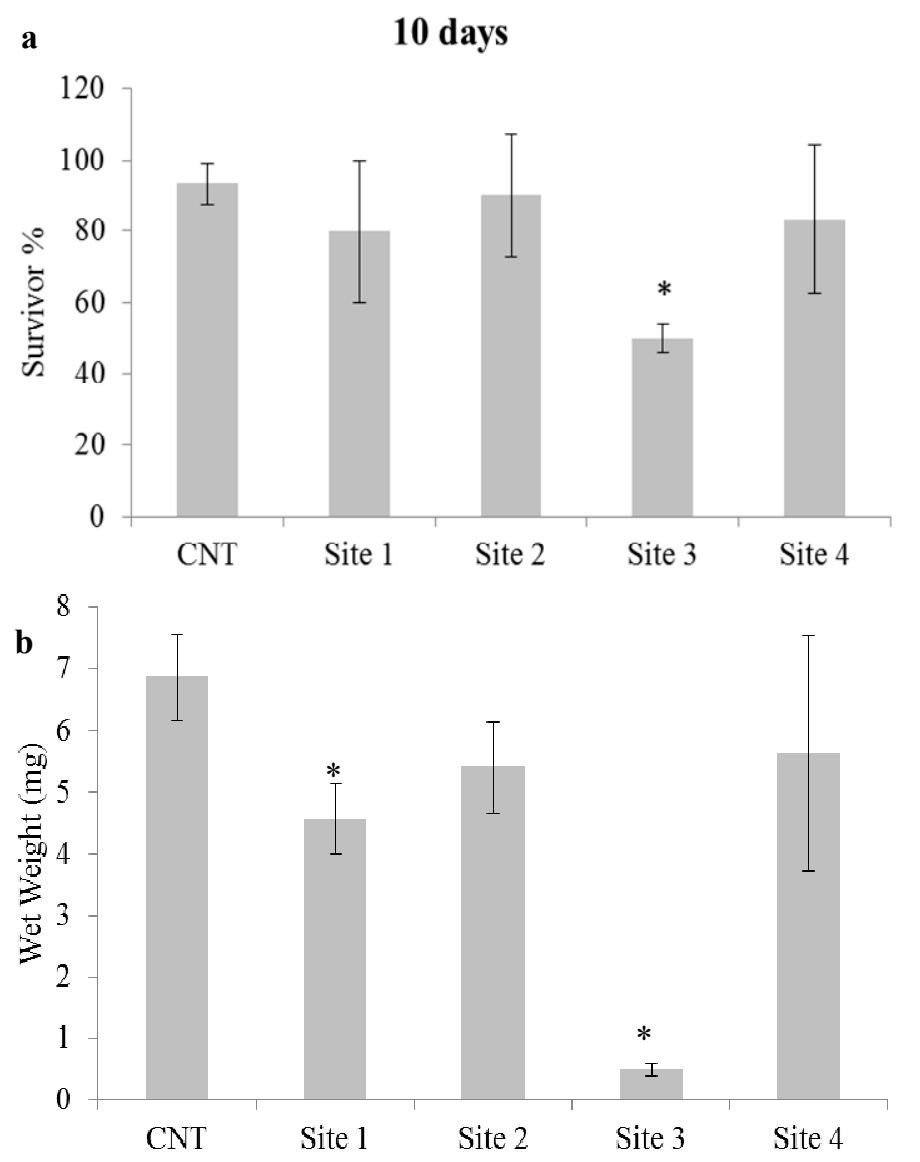

The second test lasted 25 days, five days after the last adult emerged in CNT, as recommended by [32]. The significantly lowest emergence ratio (ER) was observed at Site $3(p<0.005)$, confirming the results of the 10-day exposure; even when ERs of the other sites were lower than CNT, no significant differences existed (Figure 4). A significant delay in the development was observed at Site $3(p<0.005)$ (Figure 4). No valuable information was obtained by the sex determination of adults, showing no significant differences among sites in the number of males/females. 
Figure 4. 25-days chironomids exposure test. (a) The emergence ratio (ER $\pm \mathrm{SD}$ ) of chironomid midges for each site and the control (CNT); (b) the development rate (DR \pm SD) . Significant differences (one-way ANOVA, Dunnett's post hoc test; $p<0.005^{* *}$ ) from the control are reported.

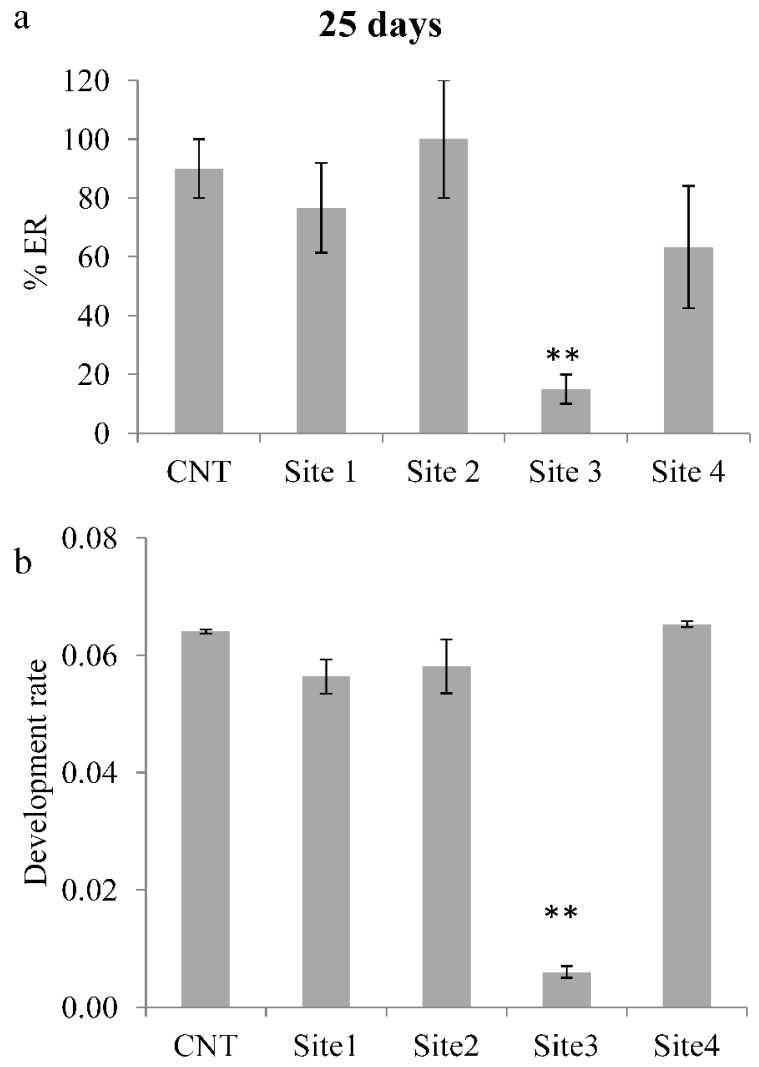

A clear correspondence between the particularly high DDT and PCB concentrations at Site 3 and the responses of the test exists. No evident relationship between the contaminant concentrations of the other sites and the results of the tests were observed, indicating that the concentrations of PCB and DDT have an evident negative relationship with the survivor/growth of benthic organisms only at Site 3 . Sediment toxicity tests conducted with the midge Chironomus dilutus (10-day exposures) have shown a significant correlation between ecotoxicity and PCB [45]. In the case of Lake Maggiore (Northern Italy), a DDT Lowest Observed Effect Concentration of $80.5 \mathrm{ng} / \mathrm{g}$ d.w. was defined for chironomids growth [46]; in the case of Lake Como, in none of the sites was this level exceeded (Table 1). In absence of quality standards for PCB in sediments, Sediment Quality Guidelines (SQGs) developed in the last 20 years may be therefore used as comparison levels. MacDonald et al. [47] developed a consensus-based sediment threshold concentration for total PCBs of $40 \mathrm{ng} / \mathrm{g}$, at which effects are unlikely to occur. Sediment collected at Site 1 and Site 2 did not exceed the reported threshold for PCB; sediments collected at Site 3 and Site 4 exceeded it, and a significant effect of chironomid emergence was observed only at Site 3, where concentrations were around five-times this threshold.

In the present work, the observed spatial variability of sediment contamination could be related to the presence of different input pollution sources, the most contaminated site (Site 3, Figure 1) being located in the port area of the city of Como. Although Como is a medium-sized city (around 85,000 inhabitants), it is a popular tourist destination, and naval activity on the lake plays an important role in 
connecting the city with most of the attractions along the shores, particularly in summer time. The port area (Figure 1, Site 2) is separated from the lake by a dike perturbing the natural renewal of water and sediment; moreover, Site 3 is next to the mouth of a small urban stream (River Valduce; Figure 1), which flows covered next to the major city hospital. Even if nothing is known of this river, during high intensity rainfall events, its flow rate can become considerable, collecting runoff water and probably hospital discharges. The River Valduce therefore represents a major sporadic point source of micropollutants for the water and sediments of this area.

\section{Conclusions}

Chemical analysis is a fundamental step in the assessment of surface water status according to WFD. However, even when all of the priority contaminant levels are known, effects on resident organisms cannot be foreseen. Therefore, the overall findings of the present work may represent an indication of the usefulness of the standard application of laboratory ecotoxicity tests in ecosystem quality assessment and the hazard ranking of water bodies receiving urban runoff and wastewater.

Moreover, although the WFD does not specifically deal with the quality of sediments, their monitoring can play a role when assessing the impacts on environmental quality, since they are a preferred matrix of accumulation of most hydrophobic contaminants along with biota.

\section{Acknowledgments}

Benedetta Ponti was financially supported by the Italian Ministry of Education, Universities and Research. Francesca Ferrario is acknowledged for the preparation of the Lake Como map. Thanks are due also to Francesca Borghi, Diana Bricalli, Giacomo Fanti, Marzio Roncoroni and Marika Zaccara for the help during sampling campaigns.

\section{Author Contributions}

Roberta Bettinetti was the supervisor of the project. Benedetta Ponti carried out all of the ecotoxicological tests and Silvia Quadroni the chemical analyses of sediments. The first and the second author discussed the results and wrote and critically revised the manuscript.

\section{Conflicts of Interest}

The authors declare no conflict of interest.

\section{References}

1. European Union: Directive 2000/60/EC of the European Parliament and of the Council Establishing a Framework for Community Action in the Field of Water Policy. Official journal of the European Communities. Available online: http://faolex.fao.org/cgi-bin/faolex.exe?rec_id= $017501 \&$ database $=$ FAOLEX\&search_type=link\&table=result\&lang=eng\&format_name=@ERALL (accessed on 1 April 2014). 
2. European Union: Directive 2013/39/EU of the European Parliament of the Council Amending Directives 2000/60/EC and 2008/105/EC as Regards Priority Substances in the field of Water Policy. Official Journal of the European Communities. Available online: http://faolex.fao.org/ cgi-bin/faolex.exe?rec_id=127344\&database=faolex\&search_type=link\&table=result\&lang=eng\& format_name=@ERALL (accessed on 1 April 2014).

3. Ademollo, N.; Patrolecco, L.; Polesello, S.; Valsecchi, S.; Wollgast, J.; Mariani, G.; Hanke, G. The analytical problem of measuring total concentrations of organic pollutants in whole water. $\operatorname{Tr} A C$ 2012, 36, 71-81.

4. Loos, R.; Gawlik, B.; Locoro, M.G.; Rimaviciute, E.; Contini, S.; Bidoglio, G. EU-wide survey of polar organic persistent pollutants in European river waters. Environ. Pollut. 2009, 157, 561-568.

5. Slobodnik, J.; Mrafkova, L.; Carere, M.; Ferrara, F.; Pennelli, B.; Schüürmann, G. Identification of river basin specific pollutants and derivation of environmental quality standards: A case study in the Slovak Republic. TrAC 2012, 41, 133-145.

6. Roots, O.; Roose, A. Hazardous substances in the aquatic environment of Estonia. Chemosphere 2013, 93, 196-200.

7. European Union. Common Implementation Strategy for the Water Framework Directive (2000/60/EC). Guidance Document No. 25 on Chemical Monitoring of Sediment and Biota under the Water Framework Directive; Office for Official Publications of the European Communities: Luxembourg, Luxembourg, 2010.

8. Wadhia, K.; Thompson, K.C. Low-cost ecotoxicity testing of environmental samples using microbiotests for potential implementation of the Water Framework Directive. $\operatorname{Tr} A C$ 2007, 26, 300-307.

9. Carere, M.; Dulio, V.; Hanke, G.; Polesello, S. Guidance for sediment and biota monitoring under the Common Implementation Strategy for the Water Framework Directive. $\operatorname{Tr} A C$ 2012, 36, 15-24.

10. Guzzella, L.; Mingazzini, M. Biological assaying of organic compounds in surface waters. Water Sci. Technol. 1994, 30, 113-1124.

11. Galassi, S.; Viganò, L.; Battaglia, C. Effetti tossici dei microinquinanti organici presenti in acque superficiali. Acqua Aria 1985, 9, 821-826.

12. Galassi, S.; Guzzella, L.; Mingazzini, M.; Viganò, L.; Capri, S.; Sora, S. Toxicological and chemical characterization of organic micropollutants in River Po waters (Italy). Water Res. 1992, 26, 19-27.

13. Galassi, S.; Guzzella, L.; Croce, V. Screening organic micropollutants in surface waters by SPE extraction and ecotoxicological testing. Chemosphere 2004, 54, 1619-1624.

14. Daignault, S.A.; Noot, D.K.; Williams, D.T.; Huck, P.M. A review of the use of XAD Resins to concentrate organic compounds in water. Water Res. 1988, 22, 803-810.

15. European Union: Directive 2008/105/EC of the European Parliament and of the Council of 16 December 2008 on Environmental Quality Standards in the Field of Water Policy. Official Journal of the European, 24 December 2008, pp. 84-97.

16. Chapman, P.M.; Anderson, J. A decision-making framework for sediment contamination. Int. Environ. Assess Manag. 2005, 1, 163-173.

17. Bettinetti, R.; Ponti, B.; Marziali, L.; Rossaro, B. Biomonitoring of lake sediments using benthic macroinvertebrates. TrAC 2012, 36, 92-102. 
18. Wenning, R.J.; Batley, G.E.; Ingersoll, C.G.; Moore, D.M. Use of Sediment Quality Guidelines and Related Tools for the Assessment of Contaminated Sediments; Wenning, R.J., Batley, G.E., Ingersoll, C.G., Moore, D.M., Eds.; SETAC: Pensacola, FL, USA, 2005; p. 815.

19. Dean, W.E., Jr. Determination of carbonate and organic matter in calcareous sediments and sedimentary rocks by loss on ignition: Comparison with other methods. J. Sediment. Petrol. 1974, 44, 242-248.

20. Salmaso, N.; Morabito, G.; Garibaldi, L.; Mosello, R. Trophic development of the deep lakes south of the Alps: A comparative analysis. Fundam. Appl. Arch. Hydrobiol. 2007, 170, 177-196.

21. Galassi, S.; Guzzella, L.; Sora, S. Mutagenic potential of drinking water from surface supplies in Northern Italy. Environ. Toxicol. Chem. 1989, 8, 109-116.

22. Guzzella, L.; Sora, S. Mutagenic activity of lake water samples used as drinking-water resources in Northern Italy. Water Res. 1998, 32, 1733-1742.

23. Guzzella, L.; Ferretti, D.; Zerbini, I.; Monarca, S. Evaluation of genotoxicity of Italian lakewater for human consumption: A case study in Lombardy. Ecotoxicol. Environ. Chem. 1999, 73, 81-92.

24. Guzzella, L.; Bellavista, D.; Monarca, S.; Feretti, D. Valutazione dell'attività genotossica delle acque del Lago di Como e localizzazione delle fonti di contaminazione. Acqua Aria 2000, 9 , 81-87.

25. Provini, A.; Galassi, S.; Guzzella, L.; Valli, G. PCB profiles in sediments of lakes Maggiore, Como and Garda (Italy). Mar. Freshw. Res. 1995, 46, 129-136.

26. Chiaudani, G.; Premazzi, G. Il Lago di Como: Condizioni ambientali attuali e modello di previsione dell'evoluzione delle qualità delle acque; Commissione delle Comunità Europee: Lussemburgo, Lussemburgo, 1993; p. 237.

27. Galassi, S.; Guzzella, L.; de Paolis, A.; Provini, A. PCBs and organochlorine pesticides in surficial sediments of Lakes Garda, Como and Maggiore. In Proceedings of the 5th International Conference on the Conservation and Management of Lakes "Strategies for lake ecosystems beyond 2000", Stresa, Italy, 17-21 May 1993; pp. 329-332.

28. Bettinetti, R.; Quadroni, S.; Galassi, S. Apporti diretti e diffusi dei DDT e dei PCB nel sottobacino comasco del Lario. In Proceedings of the XXIV National Congress SItE, Ferrara, Italy, 15-17 September 2014; p. 105.

29. Ponti, B.; Guilizzoni, P.; Lami, A.; Gerli, S.; Vezzoli, L.; Bettinetti, R.; Salemo, F.; Salmaso, N.; Veronesi, M.; Simona, M.; et al. Geochronology of Hg Pollution in Italian Sub-Alpine Lakes; SETAC World: Berlin, Germany, 2012.

30. OECD. OECD Guidelines for Testing Chemicals, Section 2: Effects on Biotic Systems. In Test No. 202: Daphnia sp. Acute Immobilization Test; OECD: Paris, France, 2004; p. 12.

31. Commissione Internazionale per la Protezione delle Acque Italo-Svizzere. Monitoraggio della presenza del DDT e di altri contaminanti nell'ecosistema Lago Maggiore, Rapporto Annuale Aprile 2002-Marzo 2003. Available online: http:/www.cipais.org/pdf/RappDDT02-03.pdf (accessed on 1 April 2014).

32. OECD. OECD Guidelines for Testing Chemicals. In Test No 218: Sediment-Water Chironomid Toxicity Using Spiked Sediment; OECD: Paris, France, 2004; p. 21.

33. Brooke, L.T.; Ankley, G.T.; Call, D.J.; Cook, P.M. Gut content weight and clearance rate for three species of freshwater invertebrates. Environ. Toxicol. Chem. 1996, 15, 223-228. 
34. Blockwell, S.J.; Pascoe, D.; Taylor, E.J. Effects of lindane on the growth of the freshwater amphipod Gammarus pulex (L). Chemosphere 1996, 32, 1795-1803.

35. Watts, M.; Pascoe, D. Use of freshwater macroinvertebrate Chironomus riparius (Diptera: Chironomidae) in the assessment of sediment toxicity. Water Sci. Technol. 1996, 34, 101-107.

36. Kosalwat, P.; Knight, A.W. Chronic toxicity of copper to a partial life cycle of the midge Chironimus decorus. Arch. Environ. Contam. Toxicol. 1987, 16, 275-282.

37. Sokal, R.R.; Rohlf, F.J. Biometry; Freeman: New York, NY, USA, 1981.

38. Fent, K.; Weston, A.A.; Caminada, D. Ecotoxicology of human pharmaceuticals. Aquat. Toxicol. 2006, 76, 122-159.

39. Neff, J.M. Bioaccumulation of organic micropollutants from sediments and suspended particulates by aquatic animals. Fresenius Zeits Analyt Chemie 1984, 319, 132-136.

40. Luckenbach, T.; Epel, D. Nitromusk and polycyclic musk compounds as long term inhibitors of cellular xenobiotic defense systems mediated by multidrug transporters. Environ. Health Perspect. 2005, 113, 17-24.

41. Pomati, F.; Orlandi, C.; Clerici, M.; Luciani, F.; Zuccato, E. Effects and interactions in an environmentally relevant mixture of pharmaceuticals. Toxicol. Sci. 2008, 102, 129-137.

42. Musolff, A.; Leschik, S.; Möder, M.; Strauch, G.; Reinstorf, F.; Schirmer, M. Temporal and spatial patterns of micropollutants in urban receiving waters. Environ. Pollut. 2009, 157, 3069-3077.

43. Daughton, C.G.; Ternes, T.A. Pharmaceuticals and personal care products in the environment: Agents of subtle change? Environ. Health Perspect. 1999, 107, 907-938.

44. RIZA. Protocol for Testing Substances in Chronic Sediment Bioassays with the Freshwater Dipteran Chironomus riparius; RIZA Protocol 09496X; RIZA: Lelystad, The Netherlands, 1996.

45. Kemble, N.E.; Hardesty, D.K.; Ingersoll, C.G.; Kunz, J.L.; Sibley, P.K.; Calhoun, D.L.; Gilliom, R.J.; Kuivila, K.M.; Nowell, L.H.; Moran, P.W. Contaminants in stream sediments from seven United States metropolitan areas: Part II-Sediment toxicity to the amphipod Hyalella azteca and the midge Chironomus dilutes. Arch. Environ. Contam. Toxicol. 2013, 64, 52-64.

46. Bettinetti, R.; Croce, V.; Galassi, S. Ecological risk assessment for the recent case of DDT pollution in lake Maggiore (Nothern Italy). Water Air Soil Pollut. 2005, 162, 385-399.

47. MacDonald, D.D.; Ingersoll, C.G.; Berger, T. Development and evaluation of consensus-based sediment quality guidelines for freshwater ecosystems. Arch. Environ. Contam. Toxicol. 2000, 39, 20-31.

(C) 2014 by the authors; licensee MDPI, Basel, Switzerland. This article is an open access article distributed under the terms and conditions of the Creative Commons Attribution license (http://creativecommons.org/licenses/by/3.0/). 